\title{
INTERDISCIPLINARY EDUCATION THROUGH THE DEVELOPMENT OF A COST-EFFECTIVE PHOTOMETRIC pH METER SENSOR USING NATURAL PIGMENTS
}

\author{
Rodolfo S. Barboza ${ }^{a, *, ®}$, Daniella L. Vale ${ }^{a}$, , Thiago C. A. Gomes ${ }^{a}$, Thayná L. Mesquita ${ }^{a}$, Carlos A. C. da Silva ${ }^{a}$ and \\ Gabriela do N. Camargo ${ }^{a}$ \\ aDepartamento de Química Analítica, Instituto de Química, Centro de Ciências Matemáticas e da Natureza, Universidade Federal \\ do Rio de Janeiro, 21941-909 Rio de Janeiro - RJ, Brasil
}

Recebido em 28/08/2021; aceito em 23/12/2021; publicado na web em 07/03/2022

\begin{abstract}
There is a trend of development of analytical methodologies and technologies that allow in situ analysis, producing accurate information in real time, at low cost, using homemade experiments and devices to increase interest in scientific knowledge with a constructive approach in an interdisciplinary perspective in Chemistry Education. In this context, a photometric-chemometric method of analysis was developed to measure the $\mathrm{pH}$ of solutions using easily accessible and low-cost material based on the use of natural pigments found in red cabbage (Brassica oleracea L.). Calibrations and determinations were performed by RGB measurements of pigment coloration in solution at different $\mathrm{pH}$ values using the free app Photometrix, converted to HSV, YCbCr and YUV color spaces and processed by Partial Least Squares regression (PLS). The best PLS model found was HSV with mean central scale obtained $\mathrm{pH}$ measurements with RMSEP $0.98, \mathrm{R}^{2} 0.97$ and bias close to zero. In addition, experimental data were statistically validated. Analyzes of predicted $\mathrm{pH}$ from three independents experiments revealed high recoveries (95-103\%) and low relative standard deviations. Thus, the PhotoMetrix app was viable for colorimetric $\mathrm{pH}$ determinations using the low-cost photometric $\mathrm{pH}$ meter sensor and a smartphone, improving accessibility and applicability in Chemistry Education.
\end{abstract}

Keywords: pH measurements; hands-on learning; Chemistry Education \& accessibility.

\section{INTRODUCTION}

The chemistry learning has had an emphasis on accumulating information from the literature than on experimental observation. ${ }^{1}$ However, many studies in the last two centuries shows that observation of experiment increases the interest in students and bring them to builders of their own knowledge. ${ }^{2}$ These ideas converge to principles of Piaget to constructivist and interdisciplinary teaching. ${ }^{3,4}$ This type of approach is related to the new structure of basic education in Brazil, called the Common National Curriculum Base. ${ }^{5}$ However, maintain a laboratory structure have a high cost and depending on the socioeconomic situation of educational Institute and the lack of investments to make chemistry teaching more effective is common. ${ }^{1,2}$ In this context the importance of designing low-cost experiments emerges.

Many studies described experiments with $\mathrm{pH}$ measurement as a practical teaching tool. ${ }^{2,6-8}$ The common measurement of $\mathrm{pH}$ in laboratories are $\mathrm{pH}$ meter and $\mathrm{pH}$ paper and other test strips. However, $\mathrm{pH}$ meter is expensive, and the electrode can be easily broken while $\mathrm{pH}$ paper is compared with a table and the error is between 0.2 to 0.5 . $^{8}$

In this context, it is interesting the use of red cabbage as natural pigment source for $\mathrm{pH}$ measurement being known as "universal indicator". ${ }^{2}$ The use of anthocyanins from red cabbage is commonly used at school and university. ${ }^{9}$

The application of natural dyes in chemical education has been used for years as a didactic resource for teaching. Gouveia-Matos in $1999^{10}$ published about natural dyes used as $\mathrm{pH}$ indicators by teachers, including the substances from red cabbage. Prior to that, GEPEQ in $1995^{6}$ discussed the use of this kind of material for acidbase equilibrium teaching.

However, the theme remains current, being not only applied, as its approach has been innovative and sophisticated as shown

*e-mail: rodolfosb@iq.ufrj.br in Hastuti et al. ${ }^{11}$ that described the use of red cabbage for $\mathrm{pH}$ measurement using Artificial Intelligence (IA) in aim to obtain an accurate mensuration. Furthermore, the use of natural pigments as a cheap and efficient material to teach chemistry has been reported in the literature for teaching several contents of chemistry, from acid-base equilibrium to organic chemistry, teaching extraction and chromatography on paper. ${ }^{9,12}$

The use of red cabbage to $\mathrm{pH}$ measurement it is not only low-cost experiment but also can be applied at home in a kitchen. Shultz et al. ${ }^{13}$ proposed this application as strategy for a homemade chemistry laboratory in remote teaching due pandemic situation. In the same context, Destino et al. ${ }^{14}$ use food colorants and smartphone to do quantitative analyses at home.

Therefore, the literature demonstrate that is important use new strategies to apply experiments to bring interesting of knowledge and construct effective skills. In this context, is important join unite widespread practices with new technologies, adding knowledge and interest. In this scenario, an approach using image capture and chemometric processing of the obtained data matrix can be used in order to obtain an accurate measurement.

In this context, the present work presents an interesting alternative for the discussion of biological/biochemical concepts (production of secondary metabolites in plants), chemical (acid-base balance and $\mathrm{pH}$-dependent structural molecular modifications), physical (optical properties and the study of color spaces) and mathematics (statistical data processing), relevant to the use of a photometric sensor to determine the $\mathrm{pH}$ of solutions, planned and built from recyclable material, accessible and cost-effective, common to the daily life of the students. Thus, an automated method was developed with smartphone image capture and multivariate calibration process through the utilization of the free app Photometrix ${ }^{15,16}$ for obtaining an array of space color images of samples and using a chemometric processing by the Partial Least Squares regression (PLS). It is important to mention that many smartphone applications, including optical detection, have 
been described in the literature as an alternative analysis technique, highlighting the potential of this type of tool for in situ analysis with good performance. ${ }^{17}$ The PLS chemometric algorithm is able to build a multivariate calibration model using second-order data to predict a given response. This tool is based on decomposition into eigenvalues and eigenvectors and regress calculation to obtain correlation of $\mathrm{X}$ and $\mathrm{Y}$ data. ${ }^{18,19}$ Therefore, this algorithm is capable of constructing a mathematical model to correlate a vector of image sample to $\mathrm{pH}$ value. Given the varied content and interdisciplinary character embedded in the proposal, the photometric $\mathrm{pH}$ meter sensor can be used to guide scientific discussions at any level of Chemistry Teaching, in an interdisciplinary way, and can also be implemented in Chemistry Teaching in the distance modality.

\section{MATERIAL AND METHODS}

\section{General}

The $\mathrm{pH}$ measurements were performed using a Metrohm potentiometer (827 $\mathrm{pH}$ Lab, METROHM, Brazil), with a combined glass electrode (6.0228.010, METROHM, Brazil) containing internal solution of $\mathrm{KCl} 3 \mathrm{~mol} \mathrm{~L}^{-1}$ saturated with $\mathrm{AgCl}$ (METLER TOLEDO, Switzerland). Buffer solutions at $\mathrm{pH} 4.00,7.00$ and $9.00 \pm 0.02$ (METROHM, Brazil) were used for the $\mathrm{pH}$ meter calibration. Ultrapure water, $\mathrm{HCl} 36,5-38 \%$ (ACS reagent grade) and $\mathrm{NaOH} \geq 97.0 \%$ pellets (ACS grade reagent) were used to prepare the solutions with different $\mathrm{pH}$ values ranging from -0.39 to 13.74 .

\section{Plant material purchase, processing and paper impregnation}

Red cabbage (Brassica oleracea L.) was purchased at a public market in Rio de Janeiro - RJ, Brazil. The red cabbage was processed in an industrial stainless-steel crusher (LIOTIPO). The main coloring compounds of the natural dye of red cabbage were impregnated in qualitative paper by compression using a clean and dried cotton filter. To dry the paper impregnated with the natural indicators, a dryer (ARNO, Brazil) was used in the "cold air" mode. The impregnation process was repeated twice and the paper was then cut into squares with $1 \mathrm{~cm}^{2}$ of area.

\section{pH paper indicator stability (validity)}

RGB color measurements were made from indicator papers prepared on different days during the 30 -day period. The papers were prepared at 5-day intervals and stored at $-16{ }^{\circ} \mathrm{C}$ and protected from light. The papers were analyzed after use as indicator paper in $\mathrm{pH} 1.07$, 7.00 and 13.13 solutions. All analyses were assayed in quadruplicate. All papers used in the RGB measurements (including papers not used) were then organized on a white plate and photographed with a 21 megapixels (MP) resolution digital camera. The plate was put at the same inclination as the digital camera, so that each set of samples was analyzed under the same conditions, in order to avoid the more common interferences..$^{20}$ The pictures obtained were processed using the Image J 1.43u image processing program (Wayne Rasband, National Institutes of Health, USA). In the first step, the pictures were inverted and then processed, in order to obtain light density measurement graphics (densitograms) (https://imagej.nih.gov/ij/ docs/menus/analyze.html\#measure). The average peak areas from the densitograms of the indicator papers for each day were calculated and normalized by the results obtained for the papers prepared at the same day of the analysis to make it possible to compare the relative efficiency of the papers as function of the time.

\section{Evaluation of the range color scale from red cabbage}

To evaluate the $\mathrm{pH}$ color scale of the red cabbage pigments as a function of $\mathrm{pH}$ value, 14 solutions with different $\mathrm{pH}$ values were prepared: $0.02 ; 1.03 ; 1.98 ; 2.99 ; 3.99 ; 5.01 ; 6.30 ; 7.01 ; 8.40$; $9.01 ; 9.94 ; 11.01 ; 11.97 ; 13.13$. For the qualitative $\mathrm{pH}$ color scale evaluation, 1 indicator paper was added to $1 \mathrm{~mL}$ of each solution, which was removed after saturation.

\section{Alternative pH meter kit construction}

The alternative $\mathrm{pH}$ meter was composed of three main parts: a lighting chamber, a sampler and an image capture system (in the case of the present study, a digital 15.5 MP cell phone camera was used). For the construction of the lighting chamber, a cardboard box was used $(33 \times 19 \times 12 \mathrm{~cm}$; length, width and height, respectively), coupled to a led lamp as a light source $(10 \mathrm{~W} ; 800 \mathrm{~lm}$ of luminous flux; 5.500 K of color temperature) (.Casanova, São Paulo, Brazil). For the construction of the sampler, cardboard strips $(3 \times 20 \mathrm{~cm}$; width and length, respectively) and a recycled medicine tablets blister pack (well size: $12 \mathrm{~mm}$ of inner diameter; $5 \mathrm{~mm}$ of depth) were used. Lighting chamber: the cardboard box was internally covered with white paper and then three strategic cutouts were made: on the upper side of the box a circular cutout with a diameter of $2 \mathrm{~cm}$ to fit the image capture camera $(\mathrm{LC} 1)$ and; a rectangular cutout $(5 \times 10 \mathrm{~cm})$ to fit the led lamp (LC2); on the side of the box a rectangular cut $(3 \times 2 \mathrm{~cm}$; width and height, respectively) was made for the sampler introduction (LC3). LC1 and LC3 were strategically placed in positions with perpendicular axes (Figure 1A). Sampler: rectangular cutouts were made on two cardboard strips; the third strip was used as the sampler base (S1). The three tapes were glued and covered with white paper.

(A)

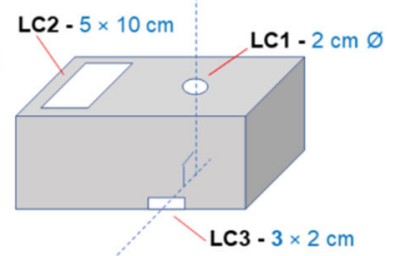

(B)
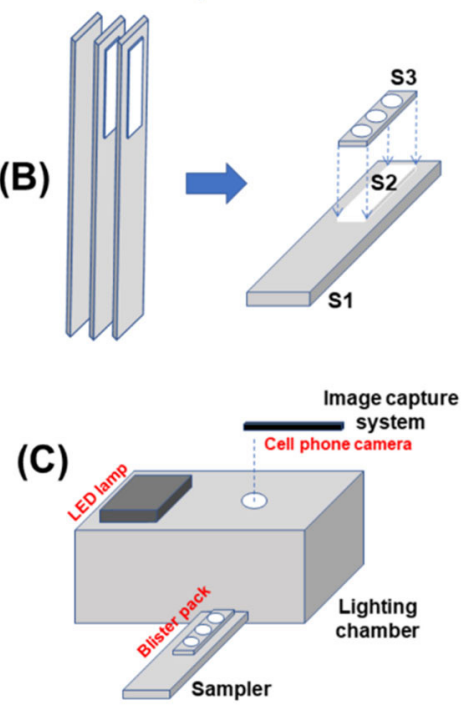

Figure 1. Alternative pH meter. (A). Lighting chamber cardboard box cutouts; (B). Sampler cardboard strips cutouts and mounting; $(C)$. Complete apparatus. LC1: cutout for camera coupling; LC2: cutout for light source coupling; LC3: cutout for sampler coupling; S1: sampler base; S2: cutout for blister pack coupling; S3: Blister pack 
In the gap formed by cutting the overlapping tapes (S2), the blister pack was fitted (S3), with three wells for triplicate analysis (Figure 1B). The complete apparatus is shown in Figure 1C.

\section{Didactic experiment}

To verify the viability and effectiveness of the proposed $\mathrm{pH}$ measurement method, a blind test was performed by analyzing three sample solutions with unknown $\mathrm{pH}$ values, using the alternative $\mathrm{pH}$ meter. The sample solutions were labeled as follows: Sample A $(\mathrm{HCl}$ solution $\left.\sim 0.1 \mathrm{~mol} \mathrm{~L}^{-1}\right)$; Sample $\mathrm{B}\left(\mathrm{NaOH}\right.$ solution $\left.\sim 0.1 \mathrm{~mol} \mathrm{~L}^{-1}\right)$; and Sample C (Tap water).

The $\mathrm{pH}$ measurements of these solutions were carried out by 30 different analysts, students of the course about Chemistry of Natural Products, during the $26^{\text {th }}$ Chemistry Week at the Institute of Chemistry at the Federal University of Rio de Janeiro.

The $\mathrm{pH}$ values obtained by the blind test were compared with values obtained by direct measurement on a traditional $\mathrm{pH}$ meter equipped with a combined glass electrode.

\section{Data acquisition}

The volume of $500 \mu \mathrm{L}$ of solutions ( $\mathrm{pH}$ range to -0.44 and 13.74) was added to the sampler wells followed by the addition of a previously prepared $\mathrm{pH}$ indicator paper. After saturation of the solutions with the pigments present in the papers, they were removed from the solution and discarded. A Motorola Moto Maxx smartphone (MOTOROLA, Illinois, USA), operating with Android 6.0.1 was used for the image capture. The camera configurations were full screen mode (16: 9) and 15.5 MP. For the analyses the free App PhotoMetrix 1.1.15 was used through the application of the Univariate Vector RGB Analysis. For the sampling a number of samples of 3 and region of interest $32 \times 32$ were used. The RGB values were determined for all solutions in triplicate.

\section{Statistical analysis}

The data processing was done with MATLAB 2013a by Mathworks ${ }^{\circledR}$ and a PLS_Toolbox by Eigenvector ${ }^{\circledR}$. The PLS was applied with a confidence level of $95 \%$ and the chosen processing was mean center scale. The RGB data was converted to HSV data using the command $r g b 2 h s v$ (). For YUV and $\mathrm{YCbCr}$ conversion were used the commands:

$\mathrm{Y}=0.299 *$ sample $(:, 1)+0.587 *$ sample $(:, 2)+0.114 *$ sample $(:, 3)$

$\mathrm{U}=-0.147 *$ sample $(:, 1)-0.289 *$ sample $(:, 2)+0.436 *$ sample $(:, 3)$

$\mathrm{V}=0.615 *$ sample $(:, 1)-0.515 *$ sample $(:, 2)-0.100 *$ sample $(:, 3)$

$\mathrm{Cb}=-0.169 *$ sample $(:, 1)-0.331 *$ sample $(:, 2)+0.500 *$ sample $(:, 3)$

$\mathrm{Cr}=0.500 *$ sample $(:, 1)+0.419 *$ sample $(:, 2)-0.081 *$ sample $(:, 3)$

sampleYUV = horzcat $(\mathrm{Y}, \mathrm{U}, \mathrm{V})$;

sample $\mathrm{YCbCr}=\operatorname{horzcat}(\mathrm{Y}, \mathrm{Cb}, \mathrm{Cr})$.

The samples were divided into two sets: samples for calibration (fourteen points between $\mathrm{pH}-0.39$ and 13.74); samples for prediction (three points at $\mathrm{pH}-0.18,8.10$ and 11.07). All samples were analyzed in triplicate.

The $\mathrm{pH}$ paper indicator stability was evaluated using hypothesis test as Analysis of Variance (ANOVA) to verify the equivalence of variance between replicates in different storage days. The $t$-student test with equivalent variances was done next to evaluate the equivalence of obtained values. Both tests were done with a confidence level of $95 \%$. The tests were done using Excel ${ }^{\circledR}$ software from the Microsoft office 365 package (Redmond, Washington, USA).

\section{THEORY}

\section{Natural pigments and colorimetric pH determinations}

The diversity of colors found in flora results from the interaction of a few classes of pigments with light. ${ }^{20}$ Generally, most natural colorants belong to one of four chemical classes: porphyrins, carotenoids, flavonoids (anthocyanins) or alkaloids (betalains). ${ }^{21,22}$ Visual indicator substances show different coloration depending on the chemical environment to which they are subjected, with important parameters such as: $\mathrm{pH}$, electric potential, complexation with metal ions and adsorption in solids. ${ }^{7,23,24}$ The substances classified as $\mathrm{pH}$ (or acid-base) indicators are organic conjugated molecules, which are generally weak acids or bases that present different colors for each related species (protonated and ionized). ${ }^{25}$ Some substances produced by the secondary metabolism of several species of plants can be used as natural $\mathrm{pH}$ indicators, the most common being anthocyanins, predominant pigments found in plants. ${ }^{24,26,27}$

Many studies are reported in the literature showing the possibility of using the pigments of several plants as natural indicators of $\mathrm{pH}$ including use in solution or impregnated in paper. ${ }^{7,10,21,22,28-31}$ There are several studies about the anthocyanins exploring or outlining systematic methods using natural extracts, including the red cabbage extract. . $^{7-11,27,29-31}$

\section{The red cabbage dye and the fundamentals of its use as a natural $\mathrm{pH}$ indicator}

An expressive number of substances produced by the secondary metabolism of plants can be used as natural $\mathrm{pH}$ indicators, with the glucoside derivatives of anthocyanidin, denominated anthocyanins (anthos - flower; kianos - blue), which are among the most important water-soluble plant pigments, ${ }^{32}$ being common. The main coloring compounds of red cabbage (Brassica oleracea L.) are anthocyanins, consisting of derivatives of cyanidin-3diglucoside-5-glucoside (base structure) (Figure 2). The glucoside residues of cyanidin-3-diglucoside-5-glucoside were described as nonacylated, monoacylated and diacylated. Sinapic, ferulic, caffeic and $p$-coumaric acids were recognized as main phenolic acids in this structure. ${ }^{33,34}$

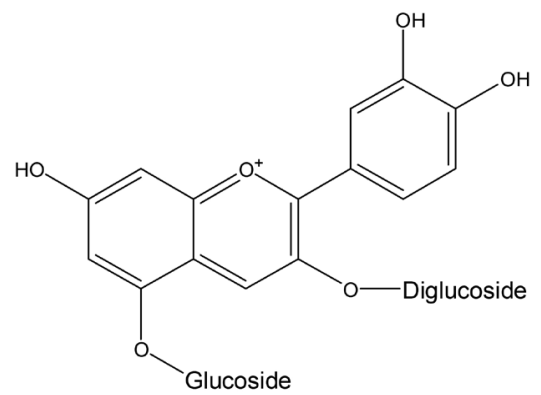

Figure 2. Base structure of anthocyanins in red cabbage (cyanidin-3diglucoside-5-glucoside)

The reason why the dye extracted from red cabbage has been used as a natural $\mathrm{pH}$ indicator is that anthocyanins have a variety of colors when subjected to chemical environments with different $\mathrm{pH}$ values. This is because the molecular structure of anthocyanidins, whose biosynthetic origin is that of flavonoids, the 15 carbon atoms being organized in the C6-C3-C6 form, has an anionic nature, ${ }^{24}$ in addition to being highly conjugated and having an acid character because it is a polyphenolic substance (weak acids). A large number of scientific papers report the color variation of anthocyanins as follows: most 
anthocyanins appear red under acidic conditions, a purple hue in neutral $\mathrm{pH}$ and blue in an increasing $\mathrm{pH}$ condition. ${ }^{7,24,32}$

The main structural changes that occur with anthocyanins depending on $\mathrm{pH}$ conditions were described in literature, which can be briefly explained as follows: ${ }^{7,32} 1<\mathrm{pH}<2$ : anthocyanins are reddish in color due to the predominance of the flavylium cation form (1); $2<$ $\mathrm{pH}<6$ : an equilibrium can be observed between the flavylium cation and a structure known as pseudobase carbinol (2). Both (1) and (2) can be converted into a structure known as quinoidal anhydrobase (3) - violet/purple, ${ }^{7}$ however, with the gradual increase in $\mathrm{pH}$, usually the color disappears due to the predominance of the pseudobase carbinol species which is colorless; $\mathrm{pH}>6$ : both the pseudobase carbinol and quinoidal anhydrobase structures can form the cis-chalcone species (4) that can be converted into the stereoisomer form transchalcone (5). When anthocyanins ionization begins, at higher $\mathrm{pH}$ values, anhydrobase structures are formed that exhibit a blue color $(\mathbf{6})$ and (7). In an extremely alkaline environment, the balance between ionized forms of cis and trans-chalcones can be observed, with a yellowish color $(\mathbf{8})$ and $(\mathbf{9})$. Structural changes in anthocyanins as a function of $\mathrm{pH}$ can be found in literature, ${ }^{7,32}$ with only a characteristic scale of colors and possible structures (Figure 3 ) being shown in this study. However, it is extremely important to understand that these colors can vary depending on various factors (the temperature, for example, is very important to the anthocyanins structures stability), the most important being the presence of copigments when it comes to natural plant extracts. ${ }^{33}$

\section{Space color theory}

Color space can be defined as tridimensional subspace which the combination can identify the color pixel. This kind of process can be applied in the projection of images displayed, to compress and process images. The most common space color for processing image data is RGB, HSV, YUV and YCbCr. It is therefore necessary to consider the major characteristics of each space color. ${ }^{35-37}$

RGB space color: the RGB space has a cubic format based in one vector for Red (R), one for Green $(G)$ and one for Blue (B), with the space color being the combination of these vectors. The scale of each vector is between 0 to $255 .{ }^{35}$

HSV space color: the HSV is a transformation of RGB space into conic space separate luminance and chrominance in Hue $(\mathrm{H})$,
Saturation (S) and Value (V). Hue describes the purity of color, Saturation is related to distribution of color in light and Value is brightness. $\mathrm{S}$ and $\mathrm{V}$ are independent components of $\mathrm{H}$ and is related with intensity. Differently of the RGB space color, the HSV have a uniform distribution space color with Euclidian distance. The range of each scale is different in this model of space, owing to the conic structure. The Hue range is between 0 and $2 \pi$, the saturation between 0 and 1 and value range from 0 to $255 . .^{35,36}$ The math of conversion between RGB to HSV is: ${ }^{35}$

$$
\begin{gathered}
\theta=\cos ^{-1}\left(\frac{(r-g)+(r-b)}{2 \sqrt{(r-g)^{2}+(r-b)(g-b)}}\right) \\
\text { Hue }+\theta \text { if } b \leq g \vee \text { Hue }=2 \pi-\theta \text { if } b>g \\
\text { Saturation }=0 \text { if } \max (r, g, b)=0 \vee \text { Saturation }=1-\frac{\min (r, g, b)}{\max (r, g, b)} \text { if } \max (r, g, b) \neq 0 \\
\text { Value }=\max (r, g, b)
\end{gathered}
$$

YUV space color: the YUV is the transformation of RGB space color in three planes. The $\mathrm{Y}$ is the component responsible to describe luminance and the other two components describe the chrominance. ${ }^{35}$

$$
\left[\begin{array}{l}
y \\
u \\
v
\end{array}\right]=\left[\begin{array}{ccc}
0.299 & 0.587 & 0.114 \\
-0.147 & -0.289 & 0.436 \\
0.615 & 0.515 & -0.1
\end{array}\right]\left[\begin{array}{l}
r \\
g \\
b
\end{array}\right]
$$

That could be described as:

$$
\begin{gathered}
y=0.299 r+0587 g+0144 b \\
u=-0.147 r-0.289 g+0.436 b \\
v=0.615 r+0.515 g-0.1 b
\end{gathered}
$$

YCbCr space color: the $\mathrm{YCbCr}$ is the transformation of RGB space color in three planes. The $\mathrm{Y}$ is the component responsible to describe luminance and the other two describe components of blue and red color. The range of $\mathrm{Y}$ is from 0 to 235 and $\mathrm{Cb} / \mathrm{Cr}$ from 0 to $240 . .^{35,38}$

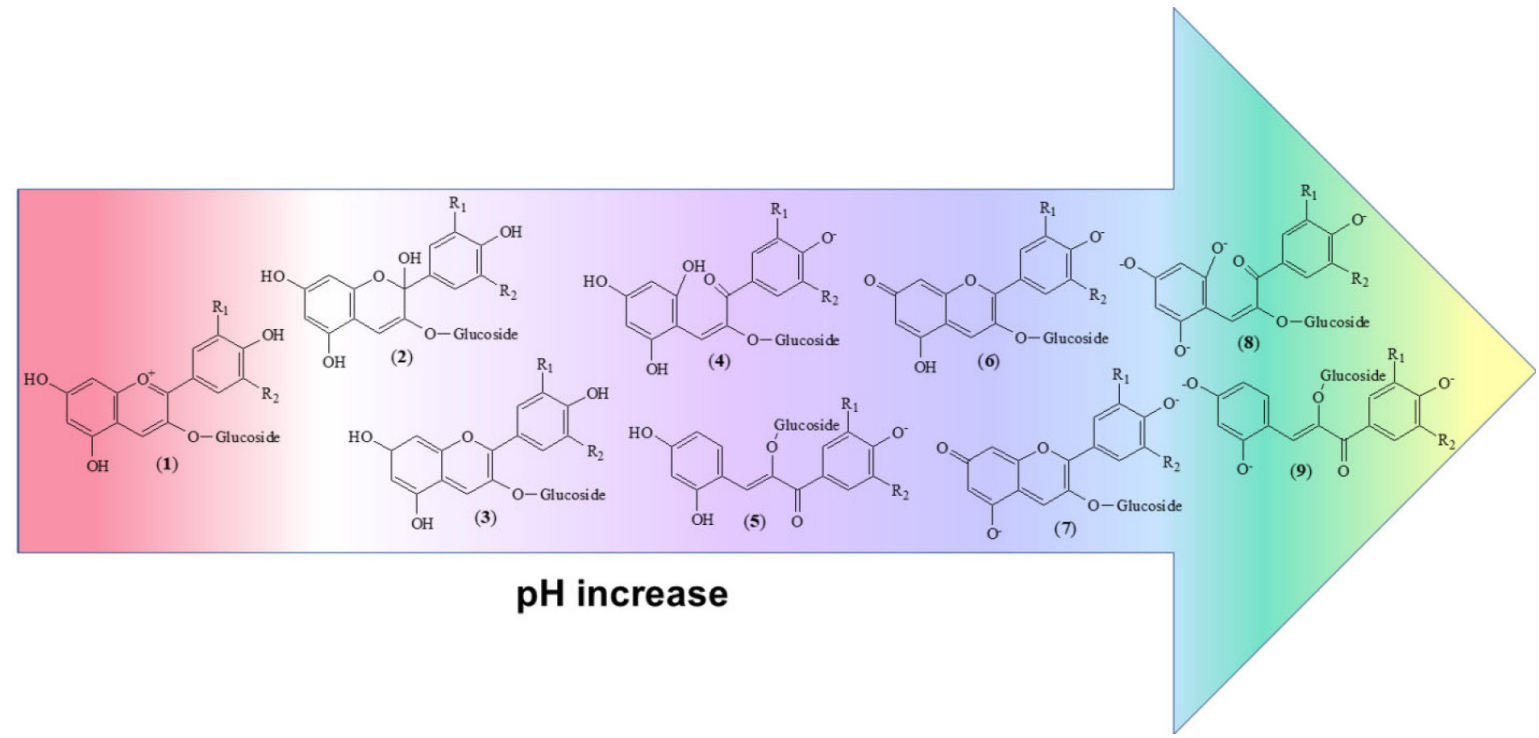

Figure 3. Substances from anthocyanins structural changes depending of pH. (1). Flavylium cation; (2). Pseudobase carbinol; (3). Quinoidal anhydrobase; (4). cis-chalcone; (5). trans-chalcone; (6) and (7). Ionic anhydrobase structures; (8) and (9). Ionic chalcones structures 


$$
\left[\begin{array}{l}
y \\
c_{b} \\
c_{r}
\end{array}\right]=\left[\begin{array}{ccc}
0.299 & 0.587 & 0.114 \\
-0.169 & -0.331 & 0.5 \\
0.5 & 0.419 & -0.081
\end{array}\right]\left[\begin{array}{l}
r \\
g \\
b
\end{array}\right]
$$

That could be described as:

$$
\begin{gathered}
y=0.299 r+0587 g+0144 b \\
c_{b}=-0.169 r-0.331 g+0.5 b \\
c_{r}=0.5 r+0.419 g-0.081 b
\end{gathered}
$$

\section{Partial Least Squares}

The pixel of one sample can be described as a vector of three terms. A set of " $n$ " samples form an array with " $n$ " lines and three columns. It is a second-order data which can be described as an array that contains the relationship between samples and their analysis data. The difficulty in evaluating the correlation of analytical data with the required information can be facilitated by reducing their dimensionality through multivariate tools (Figure 4).

Second-order multivariate analysis tools are based on the mathematics of principal component analysis, with their variations, applications, advantages and limitations. They can be classified as supervised and unsupervised methods of analysis or as calibration and classification. . $^{16,39,40}$

Partial Least Squares (PLS) is a second-order data supervised calibration tool to predict information sample. The PLS is known as a supervised model because it needs sample responses to be constructed. The decomposition and compression are done to maximize the covariance eigenvalues of $\mathrm{X}$ and $\mathrm{y}$ as Equations 1 and 2. The scores obtained from decomposition are correlated through a regression using $\mathrm{w}$ and $\mathrm{q}$ as weight (Equations 4 and 5) for the calculation of the coefficients related to each component of the model as Equations 3 and 4. ${ }^{18,19,41}$

$$
\begin{gathered}
X=T P^{T}+R_{x} \\
y=T Q^{T}+R_{y} \\
B=W\left(P^{T} W\right)^{-1} q \\
w=X^{T} y\left(y^{T} y\right)^{-1} \\
q=\left(t^{T} t\right)^{-1} t^{T} y \\
y=b_{0}+b_{1} x_{1}, b_{2} x_{2}, b_{3} x_{3}, \ldots, b N x N+\mathrm{e}_{y}
\end{gathered}
$$

In this type of method, it is important to evaluate the ideal number of components so that the model does not contain a lack of adjustment or overfitting. This evaluate can be done by root mean squared error of cross-validation (RMSECV) and root mean squared error of prediction (RMSEP). Thereafter, the generated calibration model must be validated. Validation includes evaluate the prediction power and assessing the homogeneity of residue distribution. For the first step, it is also important to evaluate the root mean squared error of calibration (RMSEC), the root mean squared error of cross-validation (RMSECV) and root mean squared error of prediction (RMSEP) and also the coefficient of determination $\left(\mathrm{R}^{2}\right) .^{41-43}$

$$
R M S E=\sqrt{\frac{\sum_{i=1}^{I}\left(y_{i}-Y_{i}\right)^{2}}{I}}
$$

The evaluation of residue can be done by bias:

$$
\text { Bias }=\frac{\sum_{i=1}^{I}\left(y_{i}-Y_{i}\right)}{I}
$$

$y_{i}$ is each value of vector y and $\hat{Y}_{i}$ is value of y predicted for the PLS model.

Mean center scale: this type of scale uses the difference between the data of column and the mean of respective column data. It is extremely important in data such as $\mathrm{HSV}, \mathrm{YCbCr}$ and YUV which have different ranges of each dimension space.

$$
x_{i j}=x_{i j}-\frac{1}{I} \sum_{1}^{I} x_{i j}
$$

\section{RESULTS AND DISCUSSION}

The great color variation presented by the anthocyanins from red cabbage extract (Figure 5), led us to choose its natural dyes for the development of an alternative, cost-effective, simple, affordable and inexpensive analytical photometric method for $\mathrm{pH}$ measurements through the use of low-cost material and tools, making it interesting because of the ease in accessibility and speed of application for laboratory (and/or classroom) routine analyses.

Before the method development, the potential of application of the natural $\mathrm{pH}$ indicator papers in science education was investigated through $\mathrm{pH}$ measurements of 3 unknown samples made by 30 analysts (chemistry students of a Natural Products Chemistry Course, taken

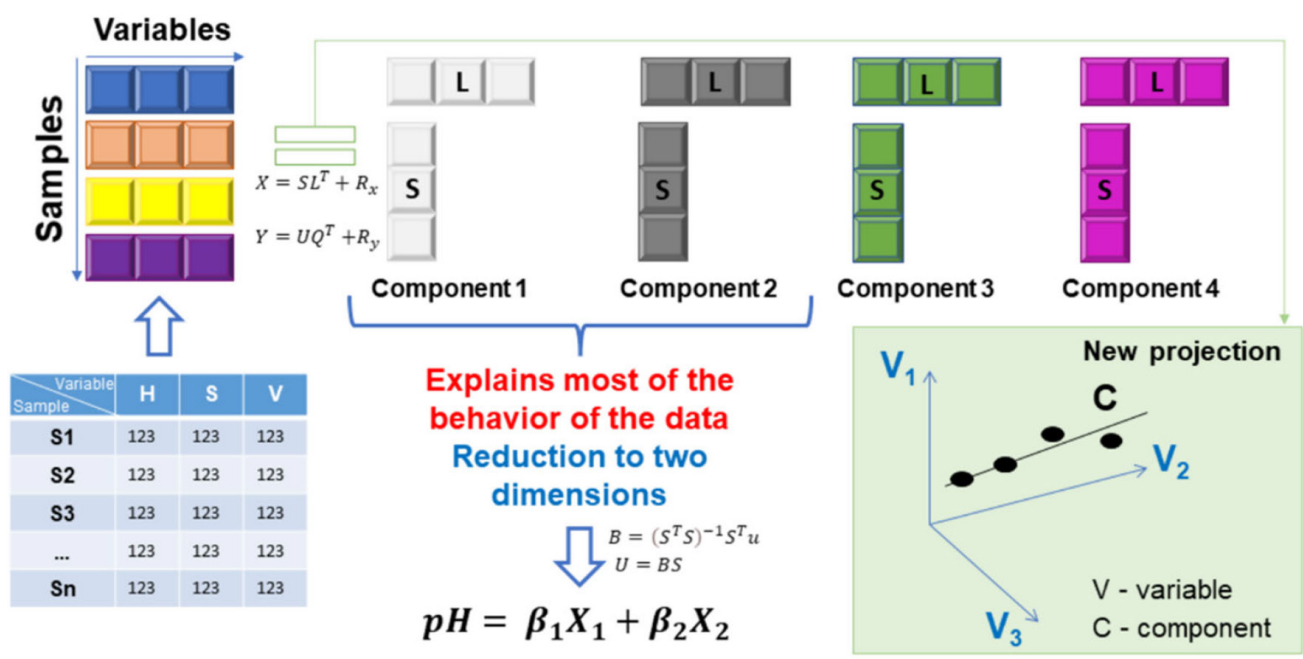

Figure 4. Dimensionality reduction scheme 


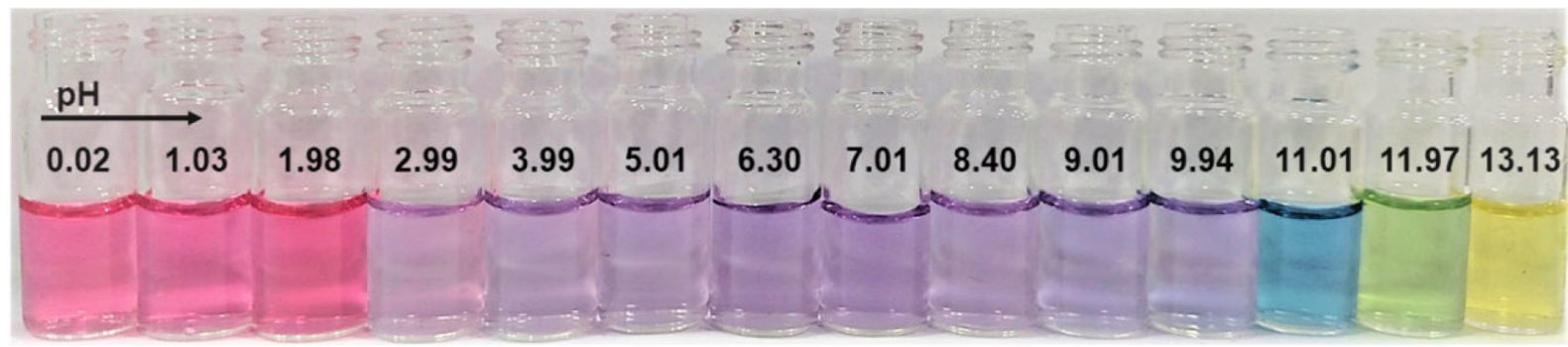

Figure 5. Red cabbage $\mathrm{pH}$ color scale

during the $26^{\text {th }}$ Chemistry Week at the Institute of Chemistry at the Federal University of Rio de Janeiro - UFRJ) (Table 1). The results obtained in the blind test demonstrated the accuracy of $\mathrm{pH}$ measurements made with indicator papers (qualitative filter paper impregnated with red cabbage dyes) when compared with the $\mathrm{pH}$ values obtained by traditional equipment. Furthermore, the alternative $\mathrm{pH}$ measurements approach was important for the discussion about the properties of the anthocyanidins from red cabbage as well as the main structural modifications according to the environment $\mathrm{pH}$ that were explored in order to use the relation between color and chemical constitution to build a simple and cost-effective $\mathrm{pH}$ measurement method.

Based on the color scale variation observed for red cabbage pigments, the $\mathrm{pH}$ measurements through the processing of the image data of the samples needed the development of an analysis system apparatus to accommodate the samples in order to maintain the same lighting conditions, distance from the camera and inclination between the subsequent analyses in order to avoid fluctuations due to causes other than the different shades and colors of the analyzed samples. For this purpose, recycled material was used, such as cardboard and medicine blister, with the developed system coupled to a low-cost effective LED lamp and a digital cell phone camera (Figure 1).

In order to verify the ease of construction of the alternative $\mathrm{pH}$ meter kit, a student from the undergraduate chemistry course at UFRJ was asked to build it, using the instructions provided in the Material and Methods. optionally, the LED lamp was replaced by a cell phone in flashlight mode (Figure 6). According to that student, the homemade $\mathrm{pH}$ meter was built in a few hours using material available in his own home.

From the use of the referred system, RGB measurement was performed in solutions of different $\mathrm{pH}$ (from -0.39 until 11.74) (Table 2), in addition to three samples: $\mathrm{HNO}_{3} 10 \%$ (v/v) (sample 1); tap water (sample 2) and; cleaning product without bleach compounds (sample 3) (Table 3).

The math model of multivariate calibration constructed with PLS algorithm using RGB, HSV, YCbCr and YUV data with mean center scale. The validations parameters determined for the four referred space colors (Table 4) were compared in order to archive the most appropriated color space for the method development.

The validation parameters analysis suggested a promising method for $\mathrm{pH}$ measurements in routine laboratory assays and teaching practices when cost effectiveness was desired using the HSV color space, which presented the lowest values of Root Mean Square Error of Calibration (RMSEC) (0.79), Root Mean Square Error of Cross Validation (RMSECV) (0.82) and Cross Validation Bias $\left(1,5 \times 10^{-3}\right)$, in addition the best values of coefficient of determination $\left(\mathrm{R}^{2}\right)$ of Calibration (0.97) and cross validation (0.97). This is probably the result of the separation between luminance and chrominance, presenting linear independence and distribution of space based on the Euclidian distance. Due to these advantages, HSV demonstrated the best correlation between the math model and the data when using PLS algorithm. Despite YCbCr and YUV having a separation between luminance and chrominance being commonly used for process image, they have a different space format compared to HSV because they do not use the Euclidian distance. Therefore, the HSV model was validated with predict set sample. The values obtained for RMSEP (0.98), Prediction Bias (0.058) and $\mathrm{R}^{2}$ of Prediction (0.98) confirmed its effectiveness for $\mathrm{pH}$ determinations with the photometric $\mathrm{pH}$ meter sensor. All discussion on method validation is available in the Supplementary Material.

In order to verify the efficiency of the proposed photometric $\mathrm{pH}$-meter sensor and validate the developed method, three different analysts (two of them were undergraduate students) determined the $\mathrm{pH}$ of water sample from a reservoir of a residential condominium in Rio de Janeiro, collected and analyzed on different days with two different

Table 1. $\mathrm{pH}$ values of the three unknown samples obtained by each student with qualitative filter paper of the red cabbage dyes

\begin{tabular}{ccccccccccccc}
\hline CS & S1 & S2 & S3 & CS & S1 & S2 & S3 & CS & S1 & S2 & S3 \\
\hline $\mathbf{0 1}$ & 2 & 13 & 6 & $\mathbf{1 1}$ & 3 & 12 & 6 & $\mathbf{2 1}$ & 3 & 13 & 6 \\
$\mathbf{0 2}$ & 2 & 13 & 6 & $\mathbf{1 2}$ & 3 & 12 & 6 & $\mathbf{2 2}$ & 3 & 13 & 6 \\
$\mathbf{0 3}$ & 2 & 14 & 6 & $\mathbf{1 3}$ & 3 & 12 & 6 & $\mathbf{2 3}$ & 1 & 13 \\
$\mathbf{0 4}$ & 2 & 14 & 6 & $\mathbf{1 4}$ & 3 & 12 & 6 & $\mathbf{2 4}$ & 1 & 13 & 6 \\
$\mathbf{0 5}$ & 3 & 12 & 8 & $\mathbf{1 5}$ & 2 & 13 & 6 & $\mathbf{2 5}$ & 1 & 13 & 6 \\
$\mathbf{0 6}$ & 3 & 12 & 8 & $\mathbf{1 6}$ & 2 & 13 & 6 & $\mathbf{2 6}$ & 1 & 13 & 6 \\
$\mathbf{0 7}$ & 3 & 12 & 8 & $\mathbf{1 7}$ & 2 & 13 & 6 & $\mathbf{2 7}$ & 1 & 13 \\
$\mathbf{0 8}$ & 3 & 12 & 8 & $\mathbf{1 8}$ & 2 & 13 & 6 & $\mathbf{2 8}$ & 1 & 13 & 6 \\
$\mathbf{0 9}$ & 2 & 13 & 5 & $\mathbf{1 9}$ & 1 & 13 & 5 & $\mathbf{2 9}$ & 1 & 13 & 6 \\
$\mathbf{1 0}$ & 2 & 13 & 5 & $\mathbf{2 0}$ & 1 & 13 & 5 & $\mathbf{3 0}$ & 2 & 12 & 3 \\
\hline & & & & & & & Average \pm SD & $\mathbf{2} \pm \mathbf{1}$ & $\mathbf{1 3} \pm \mathbf{1}$ & $\mathbf{6} \pm \mathbf{1}$ \\
\hline
\end{tabular}

CS: Chemistry Student; S1: Solution 1 (pH 1,72*); S2: Solution 2 (pH 12,71*); S3: Solution 3 (pH 6,33*); SD: Standard Deviation; *pH reference measurements were performed with a calibrated glass electrode coupled to a $\mathrm{pH}$-meter. 


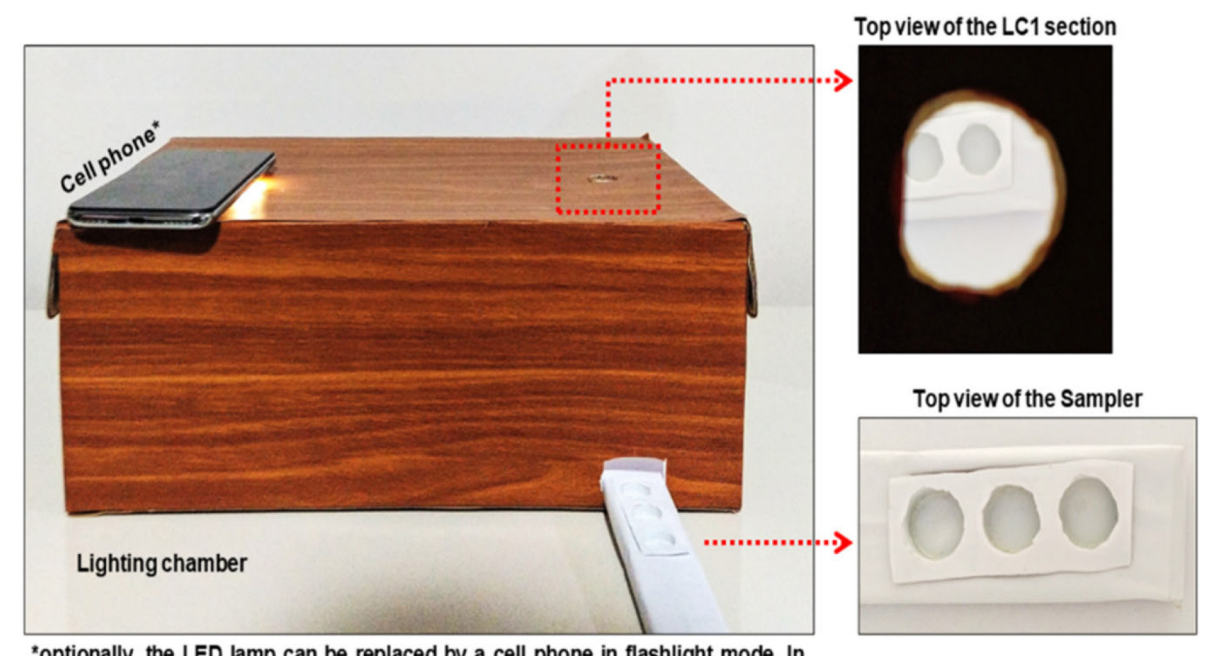

*optionally, the LED lamp can be replaced by a cell phone in flashlight mode. In the case of the present study, that light source was not used.

Figure 6. Homemade alternative $\mathrm{pH}$ meter

Table 2. RGB measurements of calibration set solutions in different $\mathrm{pH}$ values

\begin{tabular}{|c|c|c|c|c|c|c|c|c|}
\hline & M1* & M2 & M3 & SD & M1 & M2 & M3 & SD \\
\hline & \multicolumn{4}{|c|}{ pH -0.44 } & \multicolumn{4}{|c|}{ pH -0.39 } \\
\hline $\mathbf{R}$ & 138 & 138 & 137 & 0.1 & 136 & 136 & 136 & 0 \\
\hline G & 5 & 6 & 7 & 0.3 & 9 & 9 & 10 & 0.1 \\
\hline B & 44 & 44 & 43 & 0.1 & 43 & 42 & 42 & 0.1 \\
\hline & \multicolumn{4}{|c|}{ pH 2.32} & \multicolumn{4}{|c|}{ pH 3.31} \\
\hline $\mathbf{R}$ & 133 & 134 & 134 & 0.1 & 132 & 133 & 131 & 0.3 \\
\hline G & 65 & 68 & 68 & 1.0 & 91 & 91 & 91 & 0 \\
\hline \multirow[t]{2}{*}{ B } & 109 & 112 & 111 & 0.8 & 121 & 121 & 120 & 0.1 \\
\hline & \multicolumn{4}{|c|}{ pH 4.46} & \multicolumn{4}{|l|}{$\begin{array}{l}\text { pH } \\
6.50\end{array}$} \\
\hline $\mathbf{R}$ & 121 & 121 & 112 & 9.0 & 103 & 100 & 100 & 1.0 \\
\hline G & 88 & 88 & 78 & 11.1 & 81 & 75 & 76 & 3.4 \\
\hline B & 118 & 118 & 110 & 7.1 & 118 & 113 & 114 & 2.3 \\
\hline & \multicolumn{4}{|c|}{ pH 7.32 } & \multicolumn{4}{|c|}{ pH 7.55} \\
\hline $\mathbf{R}$ & 98 & 98 & 98 & 0 & 88 & 88 & 87 & 0.1 \\
\hline G & 79 & 80 & 80 & 0.1 & 72 & 71 & 70 & 0.3 \\
\hline B & 123 & 123 & 123 & 0 & 112 & 113 & 112 & 0.1 \\
\hline & \multicolumn{4}{|c|}{ pH 8.53} & \multicolumn{4}{|c|}{ pH 10.62} \\
\hline $\mathbf{R}$ & 59 & 66 & 66 & 5.4 & 16 & 19 & 20 & 1.4 \\
\hline G & 50 & 59 & 59 & 9.0 & 99 & 100 & 101 & 0.3 \\
\hline B & 100 & 106 & 105 & 3.4 & 63 & 66 & 66 & 1.0 \\
\hline & \multicolumn{4}{|c|}{ pH 11.74} & \multicolumn{4}{|c|}{ pH 12.21} \\
\hline $\mathbf{R}$ & 118 & 118 & 116 & 0.4 & 134 & 131 & 133 & 0.8 \\
\hline G & 125 & 125 & 122 & 1.0 & 133 & 130 & 132 & 0.8 \\
\hline B & 32 & 32 & 32 & 0 & 22 & 26 & 30 & 5.3 \\
\hline & \multicolumn{4}{|c|}{ pH 13.63} & \multicolumn{4}{|c|}{ pH 13.74} \\
\hline $\mathbf{R}$ & 135 & 135 & 135 & 0 & 128 & 128 & 128 & 0 \\
\hline G & 126 & 128 & 126 & 0.4 & 118 & 118 & 118 & 0 \\
\hline B & 4 & 4 & 4 & 0 & 64 & 63 & 64 & 0.1 \\
\hline
\end{tabular}

*Measurement; SD: Standard Deviation.

devices and cameras, and different images region of interest (ROI) were captured using the PhotoMetrix App (Table 5) (a step-by-step sample $\mathrm{pH}$ determination procedure is available in Supplementary Material). The $\mathrm{pH}$ of the water sample was estimated between 7-8 using a $\mathrm{pH}$ measuring tape (data not shown). Thus, it was decided to calibrate the photometric $\mathrm{pH}$-meter sensors through the analysis in triplicate of
Table 3. RGB measurements of predict set solutions in different $\mathrm{pH}$ values

\begin{tabular}{|c|c|c|c|c|}
\hline & M1* & M2 & M3 & SD \\
\hline & \multicolumn{4}{|c|}{ Sample 1 (pH -0.18) } \\
\hline $\mathbf{R}$ & 139 & 140 & 139 & 0.1 \\
\hline G & 0 & 0 & 0 & 0 \\
\hline \multirow[t]{2}{*}{ B } & 28 & 28 & 28 & 0 \\
\hline & \multicolumn{4}{|c|}{ Sample 2 (pH 8.10) } \\
\hline $\mathbf{R}$ & 93 & 94 & 94 & 0.1 \\
\hline G & 84 & 84 & 84 & 0 \\
\hline \multirow[t]{2}{*}{ B } & 115 & 115 & 115 & 0 \\
\hline & \multicolumn{4}{|c|}{ Sample 3 (pH 11.07) } \\
\hline $\mathbf{R}$ & 4 & 4 & 4 & 0 \\
\hline $\mathbf{G}$ & 83 & 84 & 81 & 0.8 \\
\hline B & 32 & 32 & 31 & 0.1 \\
\hline
\end{tabular}

*Measurement; SD: Standard Deviation.

four solutions with the following $\mathrm{pH}$ values: 1.03, 3.99, 7.01 and 9.01.

The predicted $\mathrm{pH}$ values calculated by the PLS algorithm for each solution analyzed for the analytical curves (Table 6) were used for the determination of the recovery factors (RF) (evaluation of accuracy) and relative standard deviations (RSD) (evaluation of precision $)^{44}$ (Table 7).

Recoveries ranged from $95 \%$ to $103 \%$ demonstrated that $\mathrm{pH}$ determination of solutions can be performed using the proposed method. In addition, all RDS values were less than or equal to 5\% (except the RDS values obtained for Analyst B - pH2 and Analyst $\mathrm{C}-\mathrm{pH} 1,13 \%$ and $15 \%$, respectively), suggesting a good repeatability and reproducibility, considering that different systems were used to $\mathrm{pH}$ measurements, using different cameras, lighting chamber sizes, light sources, produced papers (different plant material), amongst other parameters that can increase the interference due to variations in ambient lighting, distance between the camera and the sample surface and anthocyanidins quantities.

The analysis of variance (ANOVA) for the $\mathrm{pH}$ values obtained for the water sample by the three analysts suggested that the three analyses were significantly equivalent in evaluating the $p$-value $=$ 0.635959 (greater than the established significance level of 0.05). Furthermore, it was observed that the statistic F (0.528329) was lower than the critical F (9.552094), confirming the statistical equivalence of the results obtained for the three analyses. 
Table 4. Parameters of PLS model for $\mathrm{pH}$ measurements with red cabbage extract

\begin{tabular}{lcccc}
\hline Parameters of PLS method & Value for RGB data (LVs 2) & Value for HSV data (LVs 3) & Value for YCbCr data (LVs 2) & Value for YUV data (LVs 3) \\
\hline RMSEC & 1.76117 & 0.790536 & 1.83093 & 1.79728 \\
RMSECV & 1.83113 & 0.815826 & 1.87603 & 1.91909 \\
RMSEP* & - & 0.976883 & - & - \\
Bias & $-1.77636 \times 10^{-15}$ & $-1.77636 \times 10^{-15}$ & $-1.77636 \times 10^{-15}$ & $-1.77636 \times 10^{-15}$ \\
Cross Validation Bias: & 0.0145477 & 0.00150324 & 0.014974 & 0.00468955 \\
Prediction Bia** & - & 0.0577727 & - & - \\
$\mathrm{R}^{2}$ of Calibration & 0.858251 & 0.97144 & 0.846799 & 0.85238 \\
$\mathrm{R}^{2}$ Cross Validation & 0.84706 & 0.969586 & 0.839335 & 0.832343 \\
$\mathrm{R}^{2}$ Prediction* & - & 0.979531 & - & - \\
\hline
\end{tabular}

* Only the best model was validated with predict set sample.

Table 5. PLS regression results using PhotoMetrix to determine the $\mathrm{pH}$ water sample

\begin{tabular}{lcccc}
\hline Analyst & Day* & Device** & ROI (pixel) & $\mathrm{pH}^{* * *} \pm \mathrm{SD}$ \\
\hline $\mathrm{A}$ & 1 & $\mathrm{X}$ & $32 \times 32$ & $8.47 \pm 0.42$ \\
$\mathrm{~B}$ & 2 & $\mathrm{Y}$ & $16 \times 16$ & $8.84 \pm 0.10$ \\
$\mathrm{C}$ & 2 & $\mathrm{Y}$ & $16 \times 16$ & $8.56 \pm 0.16$ \\
\hline
\end{tabular}

*Collection and analysis day; **Photometric pH-meter sensor; *** average of the $\mathrm{pH}$ measurements for water sample; SD: Standard Deviation.

Table 6. Predicted $\mathrm{pH}$ values calculated by the PLS algorithm and determinate $\mathrm{pH}$ water sample

\begin{tabular}{lccccc}
\hline & \multicolumn{5}{c}{ Analyst A } \\
\cline { 2 - 6 } & $\mathrm{pH} 1(1.03)$ & $\mathrm{pH} 2(3.99)$ & $\mathrm{pH} 3(7.01)$ & $\mathrm{pH} 4(9.01)$ & $\mathrm{pH}$ \\
\hline R1** & 0.99 & 4.16 & 7.27 & 9.29 & 8.27 \\
R2 & 0.92 & 3.96 & 6.52 & 8.54 & 8.19 \\
R3 & 1.02 & 4.10 & 7.27 & 8.95 & 8.96 \\
\hline \multicolumn{5}{c}{ Analyst B } \\
& pH1 (1.03) & $\mathrm{pH} 2(3.99)$ & $\mathrm{pH} 3(7.01)$ & $\mathrm{pH} 4(9.01)$ & $\mathrm{pH}$ \\
\hline R1 & 1.03 & 3.47 & 6.95 & 9.03 & 8.73 \\
R2 & 0.96 & 4.47 & 6.83 & 9.05 & 8.93 \\
R3 & 1.07 & 4.33 & 6.96 & 8.97 & 8.85 \\
\hline \multicolumn{5}{c}{ Analyst C } \\
& pH1 (1.03) & $\mathrm{pH} 2(3.99)$ & $\mathrm{pH} 3(7.01)$ & $\mathrm{pH} 4(9.01)$ & $\mathrm{pH}$ \\
\hline R1 & 1.16 & 4.08 & 7.03 & 8.97 & 8.42 \\
R2 & 1.06 & 4.13 & 6.89 & 9.04 & 8.73 \\
R3 & 0.85 & 3.84 & 7.05 & 9.02 & 8.54 \\
\hline
\end{tabular}

* Water sample $\mathrm{pH}$ measurements; **Replicate.

Based on the statistical equivalence indicated by ANOVA, all results obtained by analysts $\mathrm{A}, \mathrm{B}$ and $\mathrm{C}$ were combined for comparison by $t$-student test with the $\mathrm{pH}$ of the water sample measured with the calibrated glass electrode coupled to a $\mathrm{pH}$ meter ( $\mathrm{pH}$ 8.38). The global mean $\mathrm{pH}$ was calculated at $8.62 \pm 0.22$, being considered statistically equal to the $\mathrm{pH}$ measured by the traditional instrumental method, showing a calculated $t$-value (1.494) lower than the critical $t$-value (2.306) for $95 \%$ of confidence. It is important to note that even the first water sample from the same reservoir, its $\mathrm{pH}$ was not verified by an instrumental method, being considered equal to the second water sample by statistical tests.

In this way, a didactic experiment is suggested to determine the $\mathrm{pH}$ of water in school reservoirs, given the importance of controlling the quality of the water consumed by students. In Ordinance $\mathrm{N}^{\circ} 2.914 / 2011$ (Brazilian Ministry of Health), which provides for the control and surveillance procedures for the quality of water for human consumption and its potability standard, in article $39, \S 1^{\circ}$, it is recommended that in the distribution system, the $\mathrm{pH}$ of the water is kept in the range of 6.0 to $9.5 .{ }^{45}$ However, water samples from other sources can be interesting, given the discussion of possible changes in water $\mathrm{pH} .{ }^{46}$ Furthermore, it is importance to register the numerous possibilities of the photometric $\mathrm{pH}$-meter sensor application as well as experiments involving its elements, such as the use of $\mathrm{pH}$ indicator papers for qualitative determinations of $\mathrm{pH}$ through comparison with the $\mathrm{pH}$ color scale of anthocyanidins (Figure 5), if it is not feasible to use buffer solutions.

In addition, the effectiveness of the $\mathrm{pH}$ indicator papers produced in this study was evaluated using parameters such as the amount of anthocyanidins measured by densitometry and the color change as a function of $\mathrm{pH}$ : 1.07, 7.00 and 13.13; by computational densitometry and RGB measurements, respectively. Thus, the densitometric and RGB analysis results obtained suggested that the indicator papers could be used with an interval of 0-20 days without compromising effectiveness. All discussions on the validity of $\mathrm{pH}$ indicator papers are available in the Supplementary Material.

This work evaluates not only the applicability of the validate method, but also the best color space to use in this application. After the evaluations of aforementioned models, it is possible to simplify and give more automation to the method by using only the free App Photometrix tool in view of its capacity to capture HSV, do the scale change for mean center and construct PLS model. ${ }^{47,48}$

Therefore, the use of red cabbage extract associated with the smartphone capture image in RGB followed by the HSV converse and the PLS algorithm apply was demonstrated as being a good alternative

Table 7. Recovery factors (RF) and relative standard deviations (RSD) for three analyses

\begin{tabular}{|c|c|c|c|c|c|c|}
\hline & \multicolumn{2}{|c|}{ Analyst A } & \multicolumn{2}{|c|}{ Analyst B } & \multicolumn{2}{|c|}{ Analyst C } \\
\hline & $\mathrm{RF}(\%)$ & $\operatorname{RSD}(\%)$ & $\mathrm{RF}(\%)$ & RSD (\%) & $\mathrm{RF}(\%)$ & $\operatorname{RSD}(\%)$ \\
\hline $\mathrm{pH} 1$ & 95 & 5 & 99 & 5 & 99 & 15 \\
\hline $\mathrm{pH} 2$ & 102 & 2.5 & 103 & 13 & 101 & 3.9 \\
\hline $\mathrm{pH} 3$ & 100 & 6.2 & 98.6 & 1 & 100 & 1 \\
\hline $\mathrm{pH} 4$ & 99 & 4.2 & 100 & 0 & 100 & 0 \\
\hline
\end{tabular}


for a simple, cost-effective and automatic $\mathrm{pH}$ measurements method development for use in the laboratory through the use of natural pigments found in plants. Besides that, in the case of education utilization, it could improve the scientific discussions in classes, as the alternative kit utilization could be explored in other ways by the explanation of important themes such as the distribution mechanism of anthocyanins species in their equilibrium in different $\mathrm{pH}$ values, image data processing, chemometric tools, amongst other things. In this way, the developed method could be capable of introducing multidisciplinary classes.

\section{CONCLUSIONS}

The developed method is a promising application of plant pigments for $\mathrm{pH}$ measurement with low error (0.98) and a good correlation between variables as the $\mathrm{R}^{2}$ of calibration is 0.97144 . The HSV is shown to be the best color space for this application owing to the separation between luminance and chrominance and the Euclidian distance contribution, and the model demonstrates that the HSV value is the most important term for these anthocyanins, being relative to the variation of brightness. The use of mean center scale is important due to HSV having a different range for each term. In addition, it is extremely important to note that the free App PhotoMetrix ${ }^{\circledR}$ has all the tools for multivariate analysis for HSV data processing and validation of a model for the use of natural extracts dyes as alternative $\mathrm{pH}$ indicators, leading us to the development of a simple, affordable, sustainable, cost-effective and ecofriendly method that could be used for teaching analytical chemistry concepts through didactic experiments as well as in routine laboratory assays.

\section{ACKNOWLEDGMENTS}

The authors would like to thank Conceição Marilene Silva dos Santos who kindly donated the buffer solutions used in this study and Paula Fernandes Aguiar and Raphael da Costa Mucciolo Reis for their technical support.

\section{SUPPLEMENTARY MATERIAL}

Supplementary explanation and data are available free of charge at http://quimicanova.sbq.org.br/ as a PDF file.

\section{REFERENCES}

1. Btrez, S. L.; J. Chem. Educ. 2019, 96, 193

2. Caraballo, R. M.; Medina, L. M. S.; Gomez, S. G. J.; Vensaus, P.; Hamer, M.; J. Chem. Educ. 2021, 98, 958.

3. Driver, R.; Asoko, H.; Leach, J.; Mortimer, E.; Scott, P.; Quim. Nova Esc. 1999, 9, 31.

4. Costa, E. S. C.; dos Santos, M. L.; da Silva, E. L.; Quim. Nova Esc. 2016, 38, 112.

5. Brasil, Ministério da Educação, Base Nacional Comum Curricular, 2017, disponível em: http://portal.mec.gov.br/index.php?option=com_ docman \&view $=$ download $\&$ alias $=79601$-anexo-texto-bncc-reexportadopdf-2\&category_slug=dezembro-2017-pdf\&Itemid=30192, acessado em fevereiro 2021.

6. GEPEQ; Quim. Nova Esc. 1995, 1, 32.

7. Terci, D. B.; Rossi, A. V.; Quim. Nova 2002, 25, 648.

8. Ji-Sun, K.; Han-Byeol, O.; A-Hee, K.; Jun-Sik, K.; Eun-Suk, L.; BongJun, G.; Ju-Hyeon, C.; Ye-Ji, S.; Jin-Young, B.; Ki-Sung, L.; Jae-Hoon, J.; J. Opt. Soc. Korea 2015, 19, 700.

9. Linder, J. L.; Aljic, S.; Shroof, H. M.; Di Giusto, Z. B.; Franklin, J. M.; Keaney, S.; Le, C. P.; George, O. K.; Castaneda, A. M.; Fisher, L. S.; Young, V. A.; Kiefer, A. M.; J. Chem. Educ. 2019, 96, 304.
10. Gouveia-Matos, J. A. M.; Quim. Nova Esc. 1999, 10, 6.

11. Hastuti, D. W.; Harahap, M.; Ferdiansyah, F. A.; Saputro, A. H.; Imawan, C.; J. Phys.: Conf. Ser. 2020, 1528.

12. Galloway, K. R.; Bretz, S. L.; Novak, M.; J. Chem. Educ. 2015, 92, 183.

13. Schultz, M.; Callahan, D. L.; Miltiadous, A.; J. Chem. Educ. 2020, 97, 2678.

14. Destino, J. F.; Cunningham, K.; J. Chem. Educ. 2020, 97, 2960.

15. Helfer, G. A.; Magnus, V. S.; Böck, F. C.; Teichmann, A.; Ferrão, M. F.; da Costa, A. B.; J. Braz. Chem. Soc. 2017, 28, 328.

16. da Costa, A. B.; Helfer, G. A.; Barbosa, J. L. V; Teixeira, I. D.; Santos, R. O.; dos Santos, R. B.; Voss, M.; Schlessnerd, S. K.; Barin, J. S.; J. Braz. Chem. Soc. 2021, 32, 675.

17. Jesus, J. R.; Ferrão, M. F.; da Costa, A. B.; Helfer, G. A.; Arruda, M. A. Z.; Emerging Trends in Analytical Techniques 2021, 199.

18. Ferreira, M. M. C.; Quimiometria - Conceitos, Métodos e Aplicações, $1^{\text {st }}$ ed., Ed. Unicamp: Campinas, 2015.

19. Bro, R.; J. Chemom. 1996, 10, 47.

20. Olecha, M.; Komstab, L.; Nowaka, R.; Cieślac, L.; WaksmundzkaHajnosc, M.; Food Chem. 2012, 132, 549.

21. Gonçalves, L.; Marcato, A.; Rodrigues, A.; Pagano, A.; Freitas, B.; Machado, C.; Bastos, E.; Rev. Virtual Quim. 2005, 7, 292.

22. Alkema, J.; Seagerl, S. L.; J. Chem. Educ. 1982, 59, 183.

23. Villela, A.; Van Vuuren, M. S. A.; Willemen, H. M.; Derksen, G. C. H.; Van Beek, T. A.; Dyes Pigm. 2019, 162, 222.

24. Khoo, H. E.; Azlan, A.; Tang, S. T.; Lim, S. M.; Food Nutr. Res. 2017, 61,1 .

25. Baccan, N.; Andrade, J.; Godinho, O.; Barone, J. S.; Química Analítica Quantitativa Elementar, $2^{\text {nd }}$ ed., Ed. Unicamp: Campinas, 1979.

26. Havsteen, B. H.; Pharmacol. Ther. 2002, 96, 167.

27. Guimarães, W.; Alves, M. I. R.; Filho, N. R. A.; Quim. Nova 2012, 35, 1673 .

28. Veitch, N. C.; Grayer, R. J.; Nat. Prod. Rep. 2011, 28, 1626.

29. Vankar, P. S.; Bajpai, D.; EJEAFChe, Electron. J. Environ., Agric. Food Chem. 2010, 9, 875 .

30. Soltan, M. E.; Sirry, S. M.; J. Chin. Chem. Soc. 2002, 49, 63.

31. Shukla, V.; Kandeepan, G.; Vishnuraj; M. R.; Soni, A.; Agric. Res. 2016, $5,205$.

32. Março, P. H.; Poppi, R. J.; Scarminio, I. S.; Quim. Nova 2008, 31, 1218.

33. Wiczkowski, W.; Szawara-Nowak, D.; Topolska, J.; Food Res. Int. 2013, 51,303 .

34. Fang, S.; Lin, F.; Qu, D.; Liang, X.; Wang, L.; Molecules 2019, $24,1$.

35. Garcia-Lamont, F.; Cervantes, J.; López, A.; Rodriguez, L.; Neurocomputing 2018, 292, 1.

36. Chernov, V.; Alander, J.; Bochko, V.; Computers \& Electrical Engineering 2015, 46, 328.

37. Shaik, K. B.; Ganesan, P.; Kalist, V.; Sathish, B. S.; Jenitha, J. M. M.; Procedia Computer Science 2015, 57, 41.

38. Liu, Z-G.; Du, S-Y.; Yang, Y.; Ji, X-H.; Computers \& Electrical Engineering 2014, 40, 1405.

39. De la Peña, A. M.; Goicoechea, H. C.; Escandar, G. M.; Olivieri, A. C.; Fundamentals and Analytical Applications of Multi-way Calibration, $1^{\text {st }}$ ed., Elsevier: Amsterdam, 2015.

40. Abbas, O.; Rebufa, C.; Dupuy, N.; Permanyer, A.; Kister, J.; Fuel 2012 , 98,5 .

41. Wold, S.; Sjostrom, M.; Eriksson, L.; Chemom. Intell. Lab. Syst. 2001, $58,109$.

42. Duarte, L.; Filgueiras, P.; Silva, S.; Dias, J.; Oliveira, L.; Castro, E.; de Oliveira, M. A. L.; Fuel 2016, 181, 660.

43. Vandeginste, B. G. M.; Massart, D. L.; Buydens, L. M. C.; Jong, S.; Smeyers-Verbeke, J.; Handbook of Chemometrics and Qualimetrics: Part B, $1^{\text {st }}$ ed., Elsevier Science BV: Amsterdam, 1998.

44. Ribani, M.; Bottoli, C. B. G.; Collins, C. H.; Jardim, I. C. S. F.; Melo, L. F. C.; Quim Nova 2004, 27, 771. 
45. Brasil, Ministério da Saúde, Portaria n ${ }^{\circ} 2.914$, de 12 de dezembro de 2011; Dispõe sobre os procedimentos de controle e de vigilância da qualidade da água para consumo humano e seu padrão de potabilidade. Disponível em: https://bvsms.saude.gov.br/bvs/saudelegis/gm/2011/ prt2914_12_12_2011.html, acessado em fevereiro 2021.

46. Brasil, Ministério da Saúde, Vigilância e controle da qualidade da água para consumo humano, 2006, disponível em: https://bvsms.saude.gov. br/bvs/publicacoes/vigilancia_controle_qualidade_agua.pdf, acessado em fevereiro 2021.

47. PhotoMetrix App tutorial, 2018, disponível em: http://www.photometrix. com.br/photometrix.pdf, acessado em fevereiro 2021.

48. Baumann, L.; Librelotto, M.; Pappis, C.; Santos, R. B.; Santos, R. O.; Helfer, G. A.; Lobo, E. A.; da Costa, A. B.; Águas Subterrâneas (2019), doi: 10.14295/ras.v33i2.29539. 